\section{EMBRYRIDDLE}

Aeronautical University

SCHOLARLY COMMONS
Journal of Aviation/Aerospace Education \& Research

Volume 19

Number 2 JAAER Winter 2010

Article 6

Winter 2010

\title{
Requiring Laptop Computers: Aviation Student Perceptions
}

James Higgins

Elizabeth Bjerke

Allan Skramstad

Follow this and additional works at: https://commons.erau.edu/jaaer

\section{Scholarly Commons Citation}

Higgins, J., Bjerke, E., \& Skramstad, A. (2010). Requiring Laptop Computers: Aviation Student Perceptions. Journal of Aviation/Aerospace Education \& Research, 19(2). https://doi.org/10.15394/jaaer.2010.1374

This Article is brought to you for free and open access by the Journals at Scholarly Commons. It has been accepted for inclusion in Journal of Aviation/Aerospace Education \& Research by an authorized administrator of Scholarly Commons. For more information, please contact commons@erau.edu. 


\title{
REQUIRING LAPTOP COMPUTERS: AVIATION STUDENT PERCEPTIONS
}

\author{
James Higgins, Elizabeth Bjerke and Allan Skramstad
}

\begin{abstract}
Laptop initiatives at colleges and universities have remained in low numbers despite increases in the technology and decreases in the costs. The purpose of this study was to analyze student perceptions of a university mandated laptop program which requires students to purchase an approved laptop, software, and technical support. The results of a survey administered to aviation students $(n=793)$ indicate an overall perception of value and approval for a laptop program. However, the study did reveal variances between different subsets of students. Accordingly, laptop programs and initiatives must be carefully constructed in order to be sensitive to various groups of students.
\end{abstract}

\section{Introduction}

It is estimated that nearly 150 universities require their students to have laptop computers (Carnevale \& Young, 2006). With over 4,200 institutions of higher education in the United States (Digest of Education Statistics, 2006), laptop campuses constitute a very small minority. Despite the popularity of laptop computers on college campuses, it is unclear as to why they have not made their way into the pedagogical practices of faculty. Embarking on a laptop initiative takes both economic and human resources. It is a policy decision that needs to extend beyond faculty and administrators. Understanding the needs and values of the students is imperative for a successful transition into laptop computing, and to maintain its success in and out of the classroom.

\section{Review of the Literature}

Relying solely upon popular media reports regarding laptop initiatives at universities, one could conclude a rather negative opinion. In fact, sometimes faculty are accused of banning computers in the classroom (Foster, 2008; Young, 2006), administrators are choosing to not implement well thought out plans (Olsen, 2002) and laptops are serving as a distraction limiting student learning (Foster, 2008; Young, 2006). However, empirical research conducted on laptop programs depict positive outcomes.

Tan and Morris (2005) demonstrated that students successfully achieve various levels of lifelong learning outcomes by using laptop computers. This study was conducted in conjunction with a business department requiring its junior and senior students to participate in a laptop initiative. The authors note "the cost of such a program are significant and can only be rationalized on the basis of an assessment of learning outcomes" (Tan and Morris, 2005, p.335).

Other research indicates specific learning outcomes are not the only reason colleges embark on the laptop quest. One of the goals for laptop programs is to provide all students with equal access to technology, often referred to as digital unity or ubiquitous computing. Finn and Inman (2004) found that alumni who participated in a laptop program during their undergraduate education were far more likely to support the notion of digital unity. They felt laptop computers were beneficial and a laptop program is very important for future students.

The success of a laptop program is often associated with its successful implementation. As with any new innovative pedagogy, it is vital to provide training and incentives to the faculty who are expected to participate in 
a new laptop initiative. Weaver and Nilson (2005) state "with the appropriate training in laptop technology and pedagogy, faculty could make innovative and intelligent student active use of laptops" (p. 4). Through this successful training, a survey found both faculty and students saw an increase in student engagement and learning while utilizing laptop computers in the classroom (Weaver and Nilson, 2005). Likewise, Salinas (2008) proposes that there must be a major shift in the way faculty view technology in the classroom in order for successful integration to occur.

Aviation education is unique in that it has been using computer based training through simulation and flight training devices well before the laptop computer was created. Now unique software and online tools could make the personal computer an even more valuable tool for students learning how to fly.

\section{Program Overview}

The aviation department at a four-year public university began investigating a laptop program in the early 1990s. The first iteration of the program simply requested students to bring their own laptop computer to school. In 1998, the request was changed to a requirement, and each undergraduate student within the aviation department was required to lease a computer through the school. This leasing process ensured that all students had the same computer, same software and full technical support available. The aviation department laptop program became self-supporting through fees charged to the students. The laptop initiative is only a requirement within the aviation department, the rest of the university does not require students to have a laptop computer.

Students were billed for the use of the laptops through a leasing program. Over time, the fees charged to the students have been lowered. The department also attempted to provide more technologically advanced computers with an increasing amount of software and programs available for student use. Presently, students are outfitted with a Dell $^{\circ}$ Latitude laptop computers which includes various software packages, full technical support and free printing services. The software on the computer includes, among other programs, Microsoft ${ }^{\circ}$ Office Suite, Jeppesen $^{\circ}$ Flight Star, Microsoft ${ }^{\circ}$ Flight Simulator and Vector ${ }^{\circ}$ Training system. Currently the department manages and supports over 1,500 laptop computers.

In order to fully integrate the laptop program into the curriculum, numerous facility changes had to occur. In the beginning, aviation classrooms on campus and common areas at the airport were set up with wireless capabilities.
Eventually the classroom facilities were modified in order to accommodate a hardwired, more reliable access to the internet and power supply to each seat. There are also numerous printers available for student use on campus and at the airport.

The purpose of this study is to survey students actively participating in a mature aviation department laptop program in order to answer the following research questions:

1) What are the perceptions of students regarding the aviation department laptop program?

2) To what extent do these perceptions vary between different groups of students such as academic major, grade level, and Grade Point Average (GPA)?

\section{Methodology}

Subjects

This study utilized 793 college students attending a four-year public institution and majoring in an aviation related field. The institution offers six different majors in aviation, with the two most prevalent tracks being Professional Flight (PF) and Air Traffic Control (ATC).

Subjects were chosen based upon their enrollment in certain classes. All flight classes and certain "gateway" classes within the aviation department were selected for survey presentation. The "gateway" classes were classes where the greatest department-wide permeation could be achieved while restricting subject overlap.

Materials

The survey was given via surveymonkey.com. Surveymonkey.com is a popular internet-based survey administering website. Each student was able to access the website through their leased laptop from the university. The website required no special software installations. The Institutional Review Board (IRB) approved the study and only the authorized Principal Investigators (PIs) had access to the data.

The survey was constructed by a committee of individuals who had a diverse set of subject matter expertise, including those with domain relevant experience and those with survey building experience and training. The resultant survey was administered in several sections. One section recorded demographic information, including those listed in Table 1, while another section utilized a four-point forced Likert scale to gauge laptop acceptance and measure participant perception. Additionally, several open-ended responses were recorded for qualitative analysis. 
Table 1

Selected Demographic Data

\section{Demographic}

Year in School

Major

GPA

\section{Procedures}

A research assistant visited each selected classroom to recruit student participants, answer any questions, and direct students to the survey website. The classroom visit and subsequent survey took around 20 minutes to complete. In order to ensure anonymity, a list of random numbers was generated by computer. From this list, random numbers were printed on individual pieces of paper, and placed in a box. Each participant selected one of these numbers from the box and entered it as the first question in the survey. The random number was later matched to the official roster of numbers. This procedure allowed for the study to ensure each participant was indeed a student while maintaining anonymity. All survey respondents who did not enter a correct random number were stricken from the dataset (31 surveys).

Limitations

The sample utilized in this study is composed of students in a relatively large department (around 1,550 students). The results obtained may not necessarily apply to

Table 2

Selected Survey Statements and Responses smaller programs, where customer service and customization may differ significantly. In addition, the laptop program measured in this study is mature (spanning over 10 years) when compared to newer programs. Accordingly, it is conceivable that purely ascribing student perceptions found in this program to brand new programs may produce incongruencies.

\section{Findings}

Descriptive data regarding selected aggregate survey responses is found in Table 2. There were two different global Likert statements which aimed to measure subject perspectives as it pertained to laptop program opinions. One measured perception of value and the other the overall approval rate. The Likert scale ranged from 1 to 4 where: 1 represented strongly disagree, 2 somewhat disagree, 3 somewhat agree and 4 strongly agree. In addition, survey respondents were asked to choose from a series of four choices regarding advice they would give to another program considering a laptop initiative (see Table $3)$.

\begin{tabular}{lccc}
\hline Statement & $\mathrm{n}$ & MEAN & SD \\
\hline $\begin{array}{l}\text { I believe that Aviation Department laptop program is a good } \\
\text { value. }\end{array}$ & 793 & 2.56 & 1.16 \\
$\begin{array}{l}\text { Overall, I approve of the Aviation Department laptop } \\
\text { program. }\end{array}$ & 793 & 2.81 & 1.11
\end{tabular}


Table 3

Student Advice to Other Programs

Advice Option

n

1 Students would pay a set lease rate which would include a laptop computer, required software and full technical support.

2 Students would purchase a specified laptop computer and any required software. $\quad 145$ Students would pay a set per-semester fee that would provide full technical support.

3 Students would provide their own laptop computer and any required software. Students would pay a set per-semester fee that would provide limited technical support.

$4 \quad$ Students would provide their own laptop computer and any required software. No support would be provided.

$5 \quad$ Advise against a laptop program.

79

Also, Table 4 illustrates some qualitative responses which were reflective of the prevailing sentiment expressed by the subjects.

Table 4

Selected Qualitative Responses

I use my laptop more than any other tool for aviation learning

- I like having a laptop from the school.

- I wish it cost less..., but to an extent I can understand why it costs what it does

- $\quad$ l think it is a great program...however they do not have any programs for ATC students, therefore I do not think they should pay as much for the laptop.

- I believe the laptops are a key part of our aviation system at (university). The entire department has done an excellent job of integrating them into our flight training and some of the software (particularly the systems software is impressive) However, I don't understand why we pay so much money per semester for our laptops.

- I agree that all students should be required to have a laptop for class. However, I think it would be adequate to have the option to buy your own. This way you could get a different type (Apple) if you wanted to do so.

- The idea of the aviation laptop program is a good one. However, I think it should be a rent to buy kind of situation 


\section{Main Effects}

An analysis of variance (ANOVA) was conducted to determine whether any group differences existed between student perceptions and year in school, major and GPA. Among seniors, juniors, sophomores and freshmen, a difference was found $F(3,787)=4.14, p=.006$ when students were asked about their perception of the laptop program's value (see Table 5). Post hoc breakdown using Tukey's HSD revealed the significant difference to Thable 5 between seniors $(M=2.39, S D=1.10)$ and freshmen $(M=$ $2.75, \mathrm{SD}=1.18)$. Table 6 depicts the year in school versus the subjects' overall laptop program approval. There is also a difference between grade levels $F(3,787)=5.19, p=.001$. Tukey HSD breakdown further defined the effect between seniors $(M=2.63, S D=1.08)$ and sophomores $(M=2.93$, $\mathrm{SD}=1.15)$ and between seniors and freshmen $(M=3.00$, $\mathrm{SD}=1.08)$.

ANOVA for Year in School versus Laptop Value

\begin{tabular}{ccccc}
\hline & Sum of Squares & $\mathrm{df}$ & $\mathrm{MS}$ & $\mathrm{F}$ \\
Between Groups & 16.56 & 3 & 5.52 & $4.14^{*}$ \\
Within Groups & 1048.46 & 787 & 1.33 & \\
& & & & \\
\hline${ }^{*} \mathrm{p}<.01$ & & &
\end{tabular}

Table 6

ANOVA for Year in School versus Laptop Approval

\begin{tabular}{lcccc} 
& Sum of Squares & df & MS & F \\
Between Groups & 18.87 & 3 & 6.29 & $5.19^{*}$ \\
Within Groups & 954.537 & 787 & 1.21 & \\
\hline
\end{tabular}

${ }^{*} \mathrm{p}<.01$

As shown in Tables 7 and 8, significance differences also exists between students with different majors regarding both the laptop value perception, $F(5,666)=2.89, p=<.05$, and overall laptop program approval, $F(5,666)=2.78, p<$ .05 . Post hoc analysis (Tukey HSD) reveals in both cases the difference was between PF and ATC majors. Regarding value and approval, the PF students reported means of 2.63 $(\mathrm{SD}=1.15)$ and $2.87(\mathrm{SD}=1.10)$ while the ATC students reported means of $2.25(\mathrm{SD}=1.19)$ and $2.52(\mathrm{SD}=1.18)$, respectively. 
Student Laptop Perceptions

Table 7

ANOVA for Major versus Laptop Value

\begin{tabular}{ccccc}
\hline & Sum of Squares & df & MS & F \\
Between Groups & 19.40 & 5 & 3.88 & $2.89^{*}$ \\
Within Groups & 893.17 & 666 & 1.34 & \\
& & & & \\
\hline
\end{tabular}

${ }^{*} \mathrm{p}<.05$

Table 8

ANOVA for Major versus Laptop Approval

\begin{tabular}{llllc}
\hline & Sum of Squares & df & MS & F \\
Between Groups & 17.39 & 35 & 48 & $2.78^{*}$ \\
Within Groups & 834.49 & 666 & 25 & \\
& & & & \\
\hline * $<<.05$ & & &
\end{tabular}

Finally, an ANOVA was conducted for differences between student groups by GPA. Three groups were utilized for this analysis: Group $A$, which encompassed students with GPAs from 3.50-4.00 $(n=230)$, Group $B$, which represented students with GPAs between 3.00-3.49 $(\mathrm{n}=$ 246), and Group C, which included students with GPAs between 2.50-2.99 $(n=114)$. Students with lower GPAs were not included due to their relatively low numbers ( $n=$ 2). Regarding the perception of the laptop program's value, a significant difference existed between the groups, $\mathrm{F}(2,587)$ $=6.18, p=.002$ (see Table 9). Further post hoc breakdown using Tukey's HSD revealed differences between Group A $(\mathrm{M}=2.47, \mathrm{SD}=1.17)$ and Group $\mathrm{C}(\mathrm{M}=2.84, \mathrm{SD}=1.15)$ and between Group $B(M=2.39, S D=1.12)$ and Group $C$. As shown in Table 10, when participants responded to the question regarding their overall laptop approval, significant differences between GPA groups were again demonstrated $F(2,587)=8.19, p=.000$. Post hoc analysis revealed the exact same differences between groups as seen with the value responses. In this case, means (with standard deviations in parentheses) for groups $\mathrm{A}, \mathrm{B}$, and $\mathrm{C}$ were 2.70 (1.15), 2.65 (1.09), and 3.13 (1.02). 
Table 9

ANOVA for GPA versus Laptop Value

\begin{tabular}{lrccc} 
& Sum of Squares & df & MS & F \\
Between Groups & 16.24 & 2 & 8.12 & $6.18^{*}$ \\
Within Groups & 771.20 & 587 & 1.31 & \\
& & & & \\
\hline${ }^{*} \mathrm{p}<.01$ & & &
\end{tabular}

Table 10

ANOVA for GPA versus Laptop Approval

$\begin{array}{ccccc} & \text { Sum of Squares } & \text { df } & \text { MS } & \text { F } \\ \text { Between Groups } & 19.75 & 2 & 9.87 & 8.19^{*} \\ \text { Within Groups } & 707.56 & 587 & 1.21 & \end{array}$

${ }^{*} p<.01$

Students were also asked to give advice to another program considering a laptop program (see Table 3 for choices selected). A chi-squared analysis was used to determine whether any group differences existed. Regarding grade level and advice given, the relationship approached significance, $\chi^{2}(15, \mathrm{~N}=791)=23.24, \mathrm{p}=.08$, but did not cross the alpha level threshold of .05 . There is a significant difference between advice given by PF and ATC students, $\chi^{2}(25, N=672)=47.44, p=.004$. The PF students were more likely to recommend choice 1 while the ATC students were more likely to choose choice 5 (see Table 3 ). No other significant differences were found.

Discussion and Recommendations

While not overwhelming, based upon both the quantitative and qualitative analyses, it is clear that students are amenable to a required laptop initiative. This acceptance is very sensitive to group subsets. For instance, it is very clear from the data that ATC students were not as accepting of a laptop program when compared to other groups of students. Further qualitative analysis revealed ATC students felt the laptop program was more geared to other majors and as such, there was some frustration due to the fact they were charged the same fees.

Another difference was demonstrated amongst grade levels. At first glance, it would be tempting to analyze this data as if this study were longitudinal, and surmise that student sentiment changes over time. This study is not longitudinal however, and merely represents a "snapshot" of student perceptions on the day the survey was taken. It would be overreaching to ascribe this concept of change to the subject set. However, a longitudinal design can be implemented going forward, and the current freshmen class could once again be surveyed when they become seniors to ascertain whether a change over time occurred.

It was further demonstrated that students with higher GPAs were generally less accepting of the laptop program 
and more sensitive to its value. One hypothesis to explain this finding could be due to a correlation between higher GPA students and critical thinking skills. Conceptually, perhaps students with higher GPAs are also more discerning because of such a correlation. Certainly, this notion is beyond the scope of this study; it would be interesting however to make further inquires and explorations into this question. At present, no qualitative data can reasonably explain this group difference.

In addition, students are sensitive to several issues pertaining to the value offered by a required laptop program. The concept of value was not defined for the students in the course of the survey. This was done intentionally to gauge one's perception of the concept as it relates to a laptop program. Nonetheless, it is conceivable that value has different meanings per individual. For instance, in some cases, value could simply be equated to cost and expense. For others, value might be related to the effective use of a program; or, in the immediate case, perhaps value was tied to faculty and administration laptop utilization (or perceived lack thereof). Because this study used a mixed-method design, clarity and definition of value is available. Quantitatively, the subjects' operational definition of value is unclear. However, the qualitative responses help define exactly what the students meant by value. Clearly, with the present response set, value is squarely based upon the cost of the program. Students are very cost-conscious regarding a laptop program. It is interesting to note that the same group differences observed in the global laptop value question hold when applied to the value question.

The plurality of students would recommend a fullysupported, robust, and software included laptop program. However, in keeping with the prevailing theme of group differences as they pertain to a subject's major, the ATC students would not as readily recommend such a program. In fact, they are more likely to advise against any departmentally-mandated program.

\section{Conclusion}

For any department, college, or university considering whether to institute an organization-wide laptop program wherein students would subsidize such a program, several potentially negative outcomes should be mitigated in advance of implementation. It is clear students with different majors have different technological needs. Accordingly, any laptop initiative should take this into consideration by ensuring major-specific technology is incorporated; or, students should only be offered a "least-denominator" or basic baseline laptop version. This latter option should minimize the perceptions by some students that they are subsidizing other students' usage of such a program.

Finally, it is essential that cost to the students is kept at a minimum. When decisions between advanced technology and expensive software implementations must be weighed against increased cost, laptop program administrators should generally decide on the more cost-conscious alternative. Although students may not have the absolute latest technology or the most expensive software, it is important to realize that negative perceptions rapidly increase with the slightest increase in cost.

This study only begins to address student perceptions in the use of technology during their aviation education. One of the limiting factors is that the survey was only given to students currently participating in a laptop program at one institution. Further research should be done to gauge student perceptions about technology in non-laptop programs as well as examine generational differences in technology perceptions.. Future studies can also be conducted to measure faculty perceptions of using laptops in the classroom at various different types of aviation institutions. Given the multitude of computer-based resources available for aviation education, research in this area is extremely practical and could prove to be very beneficial.t 
Elizabeth Bjerke is an assistant professor at the University of North Dakota, where she also serves as the assistant chair of assessment for the aviation department. Her research efforts extend primarily out of her assessment activities and include studying student persistence and success in collegiate aviation programs. She is also a member of the teaching faculty where she instructs undergraduate students primarily in flight related courses from private pilot up to the CFI level. Ms. Bjerke received a Ph.D. in Educational Leadership from the University of North Dakota in 2009.

James Higgins is an assistant professor at the University of North Dakota. Professor Higgins is the incoming laptop program director for the Aviation Department at the John D. Odegard School of Aerospace Sciences. He also has varied research interests which include predicting pilot performance based upon flight experience and other measurements, effects of trauma and crisis on aerospace industry workers. He is also a member of the teaching faculty where he instructs undergraduate students in crew resource management, transport category aircraft systems, and airline operations and management.

Allan Skramstad is an associate professor emeritus and retired from the University of North Dakota's Aviation Department in 2008. Prof. Skramstad was instrumental in developing, implementing and maintaining the Aviation Department's laptop program including hardware, software selection and financing solutions for the last decade. He regularly used the laptop in the classroom since the inception of the program 10 years ago. Mr. Skramstad was instrumental in developing the introduction to notebook course which introduced the laptop and the various software programs to the students in the Aviation Department. He served as the laptop program director since its inception in 1998 to 2008. 


\section{References}

Carnevale, Y. \& Young, J. R. (2006). The challenges and benefits to requiring students to buy laptops. Chronicle of Higher Education, 52(38). A39.

Finn, S. \& Inman, J. G. (2004). Digital unity and digital divide: Surveying alumni to study effects of a campus laptop initiative. Journal of Research on Technology in Education, 36(3). 297-317.

Digest of Education Statistics. (2006) Washington, DC: National Center for

Education Statistics.' Retrieved on Feb. 20, 2008 http://nces.ed.gov/ programs/digest/ d06/tables/dt06_218.asp?referrer=report

Foster, A. L. (2008). Law professors rule laptops out of order in class. Chronicle of Higher Education, 54 (40). Al.

Olsen, F. (2002). Duke U. decides against requiring freshman to own laptops. Chronicle of Higher Education, 48(18). A44.

Salinas, M. F. (2008). From Dewey to Gates: A model to integrate psychoeducational principles in the selection and use of instructional technology. Computers \& Education, 50, 652-660.

Tan, C. L. \& Morris J. S. (2005). Undergraduate college students, laptop computers, and lifelong learning. The Journal of General Education, 54(4). 316-338.

Weaver, B. E \& Nilson, L. B. (2005). Laptops in class: What are they good for? What can you do with them? New Directions for Teaching and Learning, 101, 3-13.

Young, J. R. (2006). The flight for classroom attention: Professor vs. student. Chronicle of Higher Education, 52(39). A27-A29. 